\title{
$\mathrm{Cu}-7 \mathrm{Al}-2.5 \mathrm{Si}$ 합금의 기계적 및 내식특성에 미치는 열처리 효과 \\ 이 성 열 $^{1} \cdot$ 원 종 필 ${ }^{1} \cdot$ 박 동 현 $^{1} \cdot$ 문 경 만 ${ }^{1 \dagger} \cdot$ 이 명 훈 $^{2} \cdot$ 정 진 아 $^{2} \cdot$ 백 태 실 $^{3}$ \\ ${ }^{1}$ 한국해양대학교 공대 조선기자재공학부 \\ 2한국해양대학교 해사대학 기관시스템공학부 ${ }^{3}$ 포항대학교 제철산업과 \\ (2014년 1월 11일 접수, 2014년 2월 20일 수정, 2014년 2월 24일 채택)
}

\section{Effect of the Heat Treatment on the Mechanical Property and Corrosion Resistance of CU - 7Al - 2.5Si Alloy}

\author{
Syung-Yul Lee ${ }^{1}$, Jong-Pil Won ${ }^{1}$, Dong-Hyun Park ${ }^{1}$, Kyung-Man Moon ${ }^{1,+}$, \\ Myeong-Hoon Lee', Jin-A Jeong ${ }^{2}$, and Tae-Sil Baek ${ }^{3}$ \\ ${ }^{1}$ Dept. of Marine Equipment Engineering, Korea Maritime and Ocean Univ. Busan City, Korea \\ ${ }^{2}$ Dept. of Marine Engineering System, Korea Maritime and Ocean Univ. Busan City, Korea \\ ${ }^{3}$ Dept. of Steel Industry, Pohang College, Pohang City, Korea \\ (Received January 11, 2014; Revised February 20, 2014; Accepted February 24, 2014)
}

\begin{abstract}
Recently, the fuel oil of diesel engines of marine ships has been increasingly changed to heavy oil of low quality as the oil price is getting higher and higher. Therefore, the spiral gear attached at the motor of the oil purifier which plays an important role to purify the heavy oil is also easy to expose at severe environmental condition due to the purification of the heavy oil in higher temperature. Thus, the material of the spiral gear requires a better mechanical strength, wear and corrosion resistance. In this study, the heat treatment(tempering) with various holding time at temperature of $500{ }^{\circ} \mathrm{C}$ was carried out to the alloy of $\mathrm{Cu}-7 \mathrm{Al}-2.5 \mathrm{Si}$ as centrifugal casting, and the properties of both hardness and corrosion resistance with and without heat treatment were investigated with observation of the microstructure and with electrochemical methods, such as measurement of corrosion potential, cathodic and anodic polarization curves, cyclic voltammogram, and a.c. impedance. in natural seawater solution. The $\alpha, \beta^{\prime}$ and $\gamma_{2}$ phases were observed in the material in spite of no heat treatment due to quenching effect of a spin mold. However, their phases, that is, $\beta^{\prime}$ and $\gamma_{2}$ phases decreased gradually with increasing the holding time at a constant temperature of $500{ }^{\circ} \mathrm{C}$. The hardness more or less decreased with heat treatment, however its corrosion resistance was improved with the heat treatment. Furthermore, the longer holding time, the better corrosion resistance. In addition, when the holding time was $48 \mathrm{hrs,} \mathrm{its} \mathrm{corrosion} \mathrm{current} \mathrm{density} \mathrm{showed} \mathrm{the} \mathrm{lowest} \mathrm{value.} \mathrm{The}$ pattern of corroded surface was nearly similar to that of the pitting corrosion, and this morphology was greatly observed in the case of no heat treatment. It is considered that $\gamma_{2}$ phase at the grain boundary was corroded preferentially as an anode. However, the pattern of general corrosion exhibited increasingly due to decreasing the $\gamma_{2}$ phase with heat treatment. Consequently, it is suggested that the corrosion resistance of $\mathrm{Cu}-7 \mathrm{Al}-2.5 \mathrm{Si}$ alloy can be improved with the heat treatment as a holding time for $48 \mathrm{hrs}$ at $500{ }^{\circ} \mathrm{C}$.
\end{abstract}

Keywords : $C u-7 A l-2.5 S i$ alloy, purifier, spiral gear, heat treatment, microstructure, corrosion resistance

\section{1. 서 론}

\section{오일청정기의 모터에 부착되어 있는 스파이렐 기어는 고}

\footnotetext{
${ }^{\dagger}$ Corresponding author: lab@kmou.ac.kr
}

온의 오일에 대한 내식성, 기계적강도 및 내마모성이 요구되 므로 알루미늄 및 규소가 함유된 동합금으로 제작되고 있다. 이와 같은 스파이렐 기어의 소재는 주로 일본으로 부터 수입 하여 가공 제작하고 있으며 수입소재를 사용하여야 하기 때 문에 소재비용에 대한 부담이 크고, 또한 열간 단조 및 복잡 
한 열처리과정이 수반되어 제작경비가 많이 소요되므로, 다 양한 형태의 스파이렐 기아 개발을 위해서 원가비용이 증대 하는 문제점이 있다. 따라서 스파이렐 기아 소재를 국산화하 여 소재의 원가를 절감할 수 있는 새로운 제품개발 능력을 확보할 필요가 있다고 생각된다. 그동안 황동 및 주석청동 등의 동합금은 오래전부터 사용되어왔으나 알류미늄청동의 사용은 그 역사가 오래되지 않았으며 특히 알루미늄-규소 청동의 재료개발은 더욱 최근이라 할 수 있을 것이다. ${ }^{1}$

전술한 합금재료의 주 성분인 $\mathrm{Cu}$ 는 내식성이 철보다 우수 하므로 다양한 종류의 $\mathrm{Cu}$ 합금이 제작되어 열교환기용 튜브 등 각종 구조물에 광범위하게 사용되어지고 있다. ${ }^{2)}$ 뿐만 아 니라 선박의 각종 열교환기용 해수 냉각수 파이프 내면에 부착하는 해초류와 조개류의 부착을 억제하기 위해서 $\mathrm{Cu}$ 봉 을 양극으로 하여 외부직류전원에 의해 $\mathrm{Cu}$ 이온을 용출시켜 구리이온에 의한 방오(Anti-fouling) 효과와 음극방식효과 를 이용하기도 한다. ${ }^{3-8)}$ 그러나 최근 환경오염의 증대와 더 불어 각종 산업구조물에 사용되는 구리합금의 경우 더욱 더 우수한 기계적 및 내식특성을 요구하고 있다. 그 중에서 $\mathrm{Cu}-\mathrm{Al}$ 계 합금은 우수한 내해수성과 강도를 가지고 있는 구리합금이다. 그리고 이 알루미늄청동의 특징은 고체 $\mathrm{Cu}$ 중에 $\mathrm{Al}$ 이 용해되더라도 $\mathrm{Cu}$ 의 면심입방격자가 그대로 유지 되며 $\mathrm{Cu}-\mathrm{Al}$ 합금의 미세조직이 $\alpha$ 상만으로 구성되는 고용 체이다. 따라서 $\mathrm{Cu}-\mathrm{Al}$ 계 합금의 특징은 Fig. 1 에서 알 수 있듯이 $\mathrm{Cu}-\mathrm{Zn}$ 합금 및 $\mathrm{Cu}-\mathrm{Sn}$ 합금보다도 고용강화 효과 가 크며, $\mathrm{Al}$ 농도가 증가할수록 직선적인 비례관계로 증가한 다. ${ }^{9)}$ 예를 들면 $\mathrm{Al}$ 함유량이 $8 \%$ 및 $10 \%$ 에서 경도 및 강도 가 각각 최고치를 나타내는 것으로 알려져 있다. ${ }^{10)}$ 그러나 $\mathrm{Al}$ 농도가 그 이상 증가하게 되면 여러 종류의 금속간화합물 이 존재하여 기계적 성질과 내식성이 취약하게 된다. 이의 원인은 열처리과정에서 석출하는 취약한 $\gamma_{2}$ 상 때문인 것으 로 알려져 있다. ${ }^{11)}$ 따라서 일반적으로 사용하는 $\mathrm{Cu}-\mathrm{Al}$ 합 금은 $\mathrm{Al}$ 의 최대 고용도를 초과하지 않는 농도범위의 합금이 라 할 수 있다.

한편 $\mathrm{Si}$ 가 $5 \%$ 이상 함유된 실리콘 청동은 석출에 의한 시 효경화의 효과를 기대할 수 있으나 주조성과 소성가공성이 나빠지므로 $\mathrm{Si}$ 함유량이 $4 \%$ 이하인 실리콘 청동을 사용하 고 있다. 이 조성의 실리콘 청동은 열처리효과가 적으므로 강화용 열처리는 실시하지 않고 단지 $700 \sim 750{ }^{\circ} \mathrm{C}$ 에서 어 닐링만 실시한다. 그리고 실리콘 청동은 내식성이 좋고, 용 접성도 좋으므로 휘발유, 액체산소 등의 저장탱크, 나사류, 못, 리벳, 너트, 샤프트, 부싱, 피스톤 링, 화학공업용 기구 등에 널리 사용되고 있다.

본 연구에서는 알루미늄-규소 청동을 원심주조하여 도너 츠 형태의 중공 환봉을 제작하고, 스파이렐 기어의 성능에 요구되는 기계적 강도 및 내식성에 미치는 열처리 온도 및
열처리 시간에 대하여 비교 고찰하여 보았다. 따라서 본 연 구의 결과는 스파이렐기어 소재의 국산화를 위한 기초 데이 터를 제공하는데 중요한 참고자료가 되리라 기대된다.

\section{2. 사용재료 및 실험방법}

알루미늄-규소 청동을 고주파용해로 용해한 후에 수평형 의 원심주조기에서 원심 주조하였다. 원통형의 주형 외부를 수냉하였고, 주형의 회전속도는 $700 \mathrm{rpm}$ 이었다.

원심주조재의 형태는 외경 $370 \times$ 내경 $310 \times$ 길이 $540 \mathrm{~mm}$ 의 원통관이며 원심주조재의 화학적 조성은 Table 1 과 같다.

그리고 원통형의 원심주조재를 길이 방향과 원주 방향으 로 절단하여 가로 $30 \times$ 세로 $30 \times$ 길이 $260 \mathrm{~mm}$ 의 사각봉을 제작하였다. 그리고 상기한 시험편을 가로 $40 \times$ 세로 $30 \times$ 두께 $25 \mathrm{~mm}$ 의 소형 시편을 제작하였다. 그리고 이들 소형시 편을 설정온도 $\pm 2{ }^{\circ} \mathrm{C}$ 로 제어되는 전기로에 장입하고 500 ${ }^{0} \mathrm{C}$ 의 열처리온도에서 $3,6,12,24,48$ 및 72 시간동안 각각 유지한 후에 시편을 유냉하였다.

열처리가 완료된 시편은 두께 방향으로 약 절반 되는 위치 를 두께 방향과 수직이 되는 방향으로 고속의 수냉 회전커트 기로 절단하였다. 절단된 면은 연마 및 정마하여 경도 측정, 미세조직을 관찰하고 내식성에 대한 전기화학적 실험을 실 시하였다. 경도측정은 대경사제 모델의 브리넬 경도기를 사 용하였고, 사용압자는 직경 $10 \mathrm{~mm}$ 의 강구이며, 적용 하중은 $3,000 \mathrm{~kg}$, 하중시간은 15 초 이다. 평면으로 연마된 한 개의 시편에 대하여 4 점의 측정위치에서 브리넬 경도를 측정하였 다. 한편, 조직사진을 측정하기 위하여 직경 $3 \mu \mathrm{m}$ 의 다이아몬 드로 연마하여 평탄한 거울면을 얻은 후 $\left(\mathrm{FeCl}_{3} \cdot 6 \mathrm{H}_{2} \mathrm{O}\right.$ $10 \mathrm{~g}+\mathrm{HCl} 20 \mathrm{ml}+$ 메틸알콜 $20 \mathrm{~m} \ell$ ) 의 에칭액에 25 초간 침지하고 에칭이 완료된 후에는 물로 세정하고, 다시 알콜을 분무하여 블로어로 건조시켰다.

그리고 전기화학적 내식성 실험을 위해 시험편을 샌드페 이퍼 100 번에서 2000 번까지 연마한 후 노출면적 $1 \mathrm{~cm}^{2}$ 만을 남기고 나머지는 실리콘 수지로 절연 시켰으며 가장자리에 구멍을 딿고 동선을 연결하여 시험편을 제작하였다. 시험용 액은 천연해수용액을 사용하였으며 용존산소의 농도 차에 의 한 농도분극 및 부식생성물에 의한 실험결과의 오차를 최소화 하기 위해 $3 \mathrm{~cm} / \mathrm{s}$ (PIV: Particle Image Velocimetery 로

Table 1. Chemical composition of centrifugal casting specimen

(wt.\%)

\begin{tabular}{c|c|c|c|c|c|c|c|c|c}
\hline $\mathrm{Cu}$ & $\mathrm{Sn}$ & $\mathrm{Pb}$ & $\mathrm{Zn}$ & $\mathrm{As}$ & $\begin{array}{c}\mathrm{Ni} \\
\text { (incl } \\
\mathrm{Co})\end{array}$ & $\mathrm{Fe}$ & $\mathrm{Al}$ & $\mathrm{Mn}$ & $\mathrm{Si}$ \\
\hline rem. & 0.20 & 0.05 & 0.50 & 0.15 & 0.25 & 0.30 & 7.1 & 0.10 & 2.0 \\
\hline
\end{tabular}




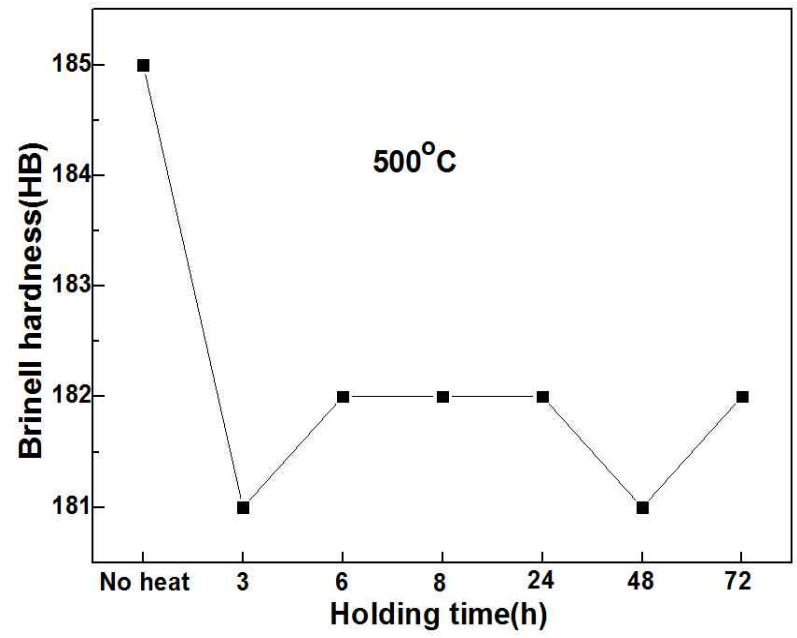

Fig. 1. Relationship between brinell hardness and holding time(h) at $500{ }^{\circ} \mathrm{C}$.

측정)의 속도로 용액을 유동시키면서 측정하였다. 측정방법 은 부식전위 변화와 양극 및 음극분극곡선의 측정과 Stern-geary 식에 근거한 컴퓨터 프로그램에 의해 부식전 류밀도를 측정하였다. 그리고 사이클릭 볼타모그램 변화와 임피던스(교류: $0.1 \mathrm{~Hz}$ 에서 $10^{4} \mathrm{~Hz}$ ) 를 측정하고 분극곡선 측정 후의 부식된 표면을 관찰하였다.

실험에 사용된 측정장치는 Won. A. Tech사가 수입 판매 하는 $\mathrm{CMS}-100$ 프로그램이며 기준전극은 SCE전극, 대극 은 백금을 사용하였고 주사속도는 $1 \mathrm{mV} / \mathrm{s}$, 그리고 delay time 은 1800초로 하였다. 단 사이클릭 볼타모그램의 측정은 $+2.0 \mathrm{~V} \sim-0.65 \mathrm{~V}$ 영역에서 $30 \mathrm{mV} / \mathrm{s}$ 의 주사속도로 하였으며 부식된 표면사진은 멀티미디어 영상현미경 (Sometech사, Model: SV35)으로 200배 배율로 관찰하였다.

\section{3. 실험 결과 및 고찰}

\section{1 기계적 성질에 대한 고찰}

Fig. 1은 $500{ }^{\circ} \mathrm{C}$ 의 일정 온도에서 $3 \mathrm{~h}$ 에서 $72 \mathrm{hrs}$ 까지 열처리한 후 유냉하였을 때, 각각의 열처리 시간에 따른 브 리넬 경도 측정값을 나타내고 있다. Fig. 1에서 알 수 있듯 이 $500{ }^{\circ} \mathrm{C}$ 에서 열처리한 경우 열처리 유지시간에 관계없이 열처리하지 않은 경우에 비해서 다소 낮은 경도값을 나타 내고 있음을 알 수 있다. 그리고 열처리 유지시간이 증가해 도 경도값은 큰 변화가 없는 것으로 생각된다.

Fig. 2는 열처리 하지 않은 원심주조재의 광학현미경 조 직사진을 보여주고 있으며 촬영 배율은 100,200 배 및 500 배로 하였다. 그리고 $\mathrm{Cu}-\mathrm{Al}$ 합금에 대한 상태도와 연속냉 각에 의한 상변태 곡선에 의하면 ${ }^{11)} \mathrm{Fig}$. 3에서 나타나는 중 간 정도의 콘트라스트 즉 주황색 영역이 $\mathrm{Cu}$ 의 격자와 같은 $\alpha$ 고용체이고, 밝은 영역의 백색이 마르텐사이트인 $\beta^{\prime}$ 상이 다. 또한 Fig. 3의 500배 배율에서 짙은 보라색의 점이 $\gamma_{2}$ 상이다. 그런데 열처리 하지 않은 원심주조재에 대한 X-선 회절에서도 $\alpha$ 상과 $\beta^{\prime}$ 상이 존재하고 있음을 나타내고 있 다. 이와 같이 급냉시에 발생되는 $\beta^{\prime}$ 상이 원심주조재에도 출현하는 이유는 원심주조에 사용되는 회전 금형이 수냉되 기 때문에 원심주조재도 급냉에 의한 열처리효과가 있기 때 문으로 생각된다.

Fig. 3 은 $500{ }^{\circ} \mathrm{C}$ 에서 일정시간 유지했을 경우의 조직사진 의 변화를 보여주고 있다. Fig. 3에서 알 수 있듯이 열처리 에 의해서 결정입자의 크기가 조대화하는 경향이 있음을 알 수 있다. 또한 열처리를 하지 않았을 경우의 결정입내의 $\beta^{\prime}$ 상과 결정입계에 존재하는 $\gamma_{2}$ 상이 열처리에 의해서 감소하 고 $\alpha$ 상이 증가하는 경향을 알 수 있다. 결국 $500{ }^{\circ} \mathrm{C}$ 의

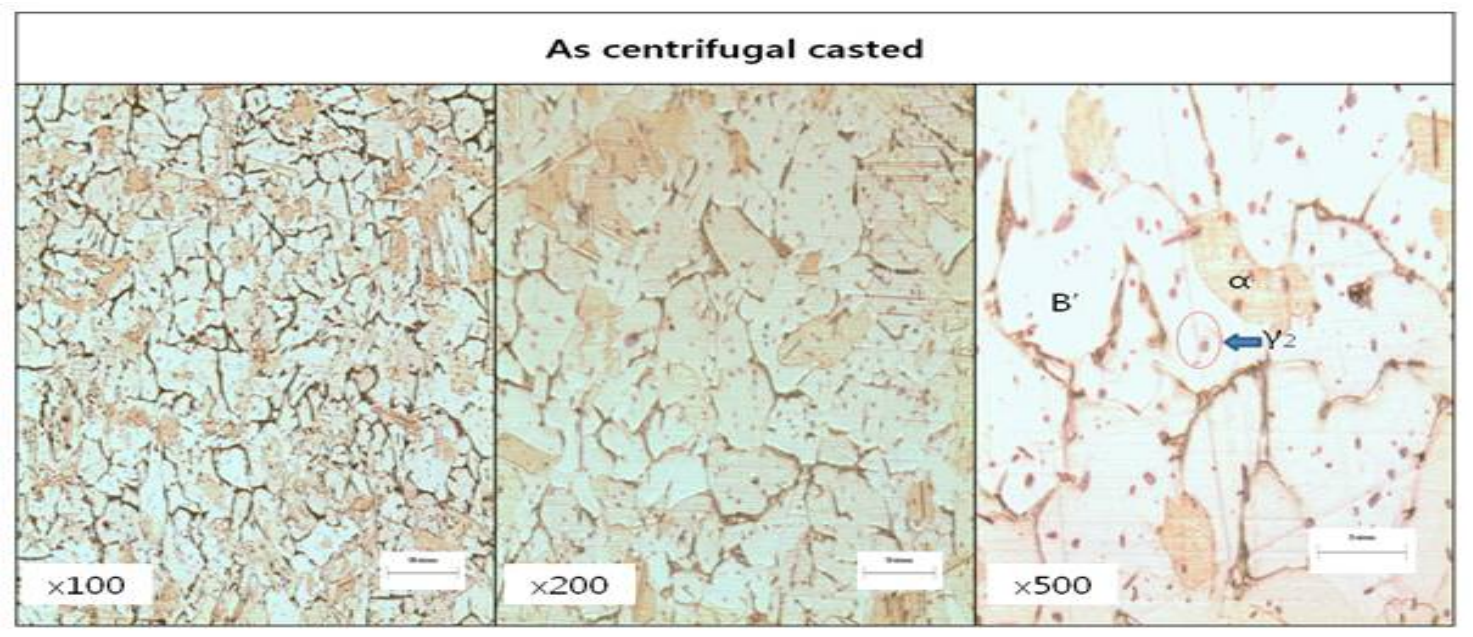

Fig. 2. Optical microstructures of centrifugally casted $\mathrm{Cu}-7 \mathrm{Al}-2.5 \mathrm{Si}$ alloy. 


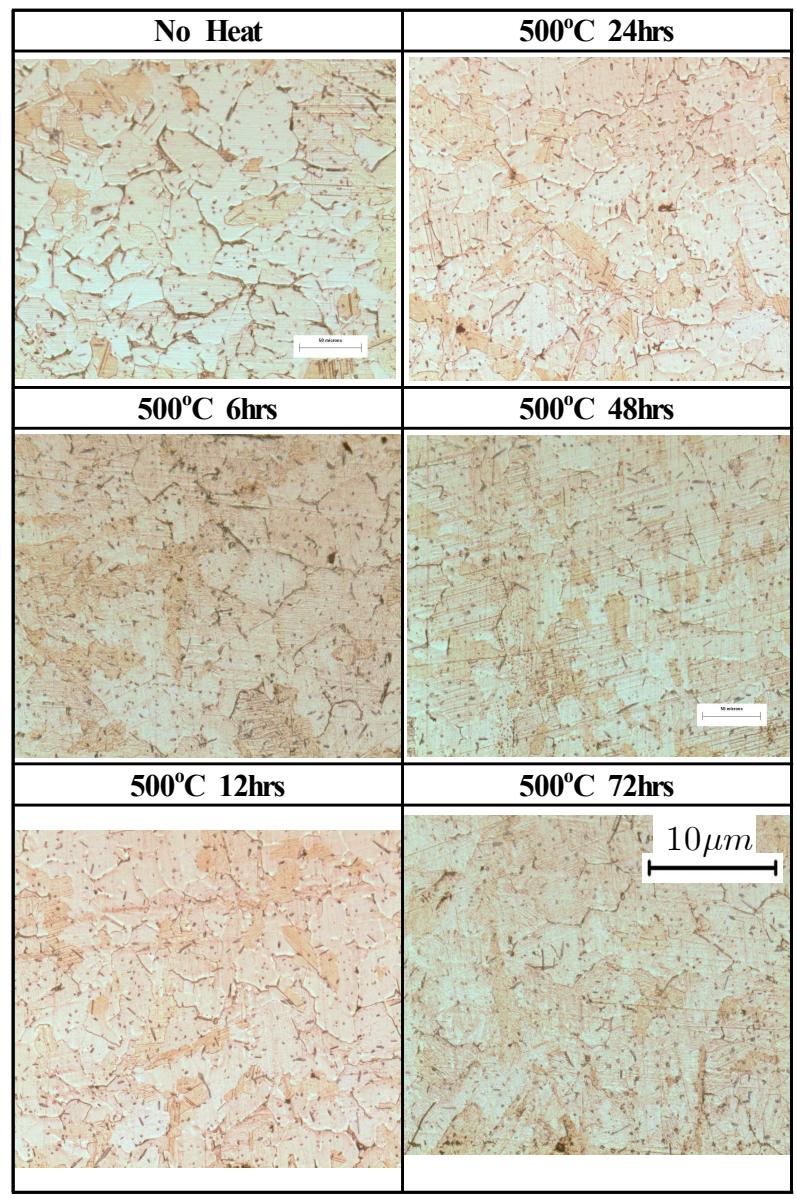

Fig. 3. Variation of microstructures with holding time at $500{ }^{\circ} \mathrm{C}$. 열처리는 뜨임열처리(tempering)이며 $\beta^{\prime}$ 상의 감소에 의 해서 경도가 다소 낮아지는 것으로 판단된다.

\section{2 내식성에 대한 전기화학적 고찰}

Fig. 4 는 $500{ }^{\circ} \mathrm{C}$ 에서 일정시간 유지한 각 시험편의 부식 전위변화를 나타내고 있다. 48시간 유지한 시험편의 경우 가장 높은 전위를 나타내고 있으며 12 시간 유지한 시험편이 가장 낮은 부식전위를 나타내고 있음을 알 수 있다. 그리고 열처리 유지시간이 길수록 부식전위는 높은 값을 나타내는 경향이 있음을 알 수 있었다. 일반적으로 부식전위가 해수용 액에서 높은 값을 나타내면 염소이온에 의한 피막의 파괴가 억제되어 부식전위를 형성하는 양극분극이 큰 값을 가지므 로 정성적으로 내식성이 좋은 것으로 평가된다. 따라서 부식 전위가 높은 48시간의 시험편이 정성적으로 내식성이 좋은 것으로 생각되나 다른 실험결과와 종합해서 판단할 수 있으 리라 생각된다.

Fig. 5는 각각의 열처리 유지시간 변화에 따른 각 시험편 의 양극 및 음극분극곡선의 변화를 나타내고 있다. 그림에서 알 수 있듯이 음극분극곡선에서 약 $-1.0 \mathrm{~V}(\mathrm{SCE})$ 영역까지

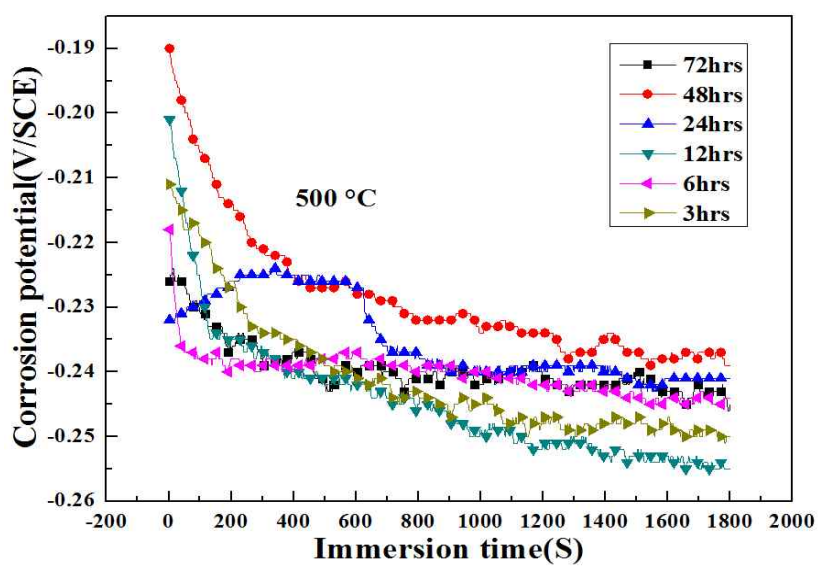

Fig. 4. Time dependence of corrosion potentials with various holding time at $500{ }^{\circ} \mathrm{C}$.

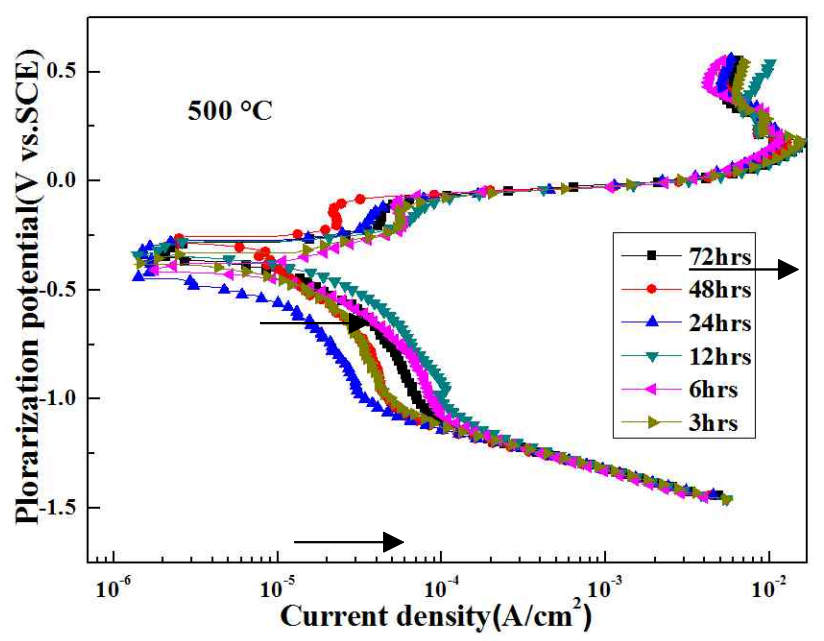

Fig. 5. Variation of cathodic and anodic polarization curves with holding time.

는 용존산소환원반응에 따른 농도분극이 나타나고 있음을 알 수 있으며 양극분극곡선에서는 약 $0.0 \mathrm{~V}(\mathrm{SCE})$ 까지 1차 부동태가 나타나고 약 $0.25 \mathrm{~V}(\mathrm{SCE})$ 에서 피크전류밀도가 나타나는 외형상의 2차 부동태가 나타나고 있음을 알 수 있다. 그리고 음극분극곡선에서 농도분극의 확산한계전류 밀도는 24시간에서 가장 적은 값을 나타내고 있으며 그리고 12 시간의 경우가 가장 큰 값을 나타내고 있다. 일반 강 구조 물의 경우 부식전위의 형성이 음극의 용존산소 환원반응에 따른 농도분극에서 형성되어 확산한계전류밀도 값을 부식 전류밀도 값으로 평가하기도 한다. 그러나 본 실험에서 사용 한 시험편은 알루미늄-규소 청동으로 일반구조용 강에 비 해서 해수에서의 내식성이 우수하므로 부식전위는 내부분 극곡선상의 용존산소의 환원반응에 의한 활성화 분극과 양 극의 부동태 영역에 근접한 즉 일반강보다 상대적으로 높은 전위에서 부식전위가 형성되기 때문에 확산한계전류밀도 
값의 대소가 내식성에 직접 영향을 미치는 것은 아니라고 생각된다. 그리고 양극분극곡선에서 1차부동태의 전류밀 도 값은 48시간의 경우가 다른 시험편에 비해서 상대적으로 적은 값을 나타내고 있음을 알 수 있다. 한편 분극곡선에 의한 부식전류밀도의 측정은 다음의 이론식에 근거해서 구 할 수 있다. 즉 Butler-volmer의 이론식은 다음의 (1)식으 로 나타낼 수 있다. ${ }^{2)}$ 그리고 (1)식에서 분극곡선상의 양극 및 음극의 분극전위가 $20 \mathrm{mV}$ 내의 영역에서는 stern-geary 식 즉 (2)식으로 변형해서 부식전류밀도를 측정할 수 있 다. ${ }^{13)}$ 그리고 (2)식에 근거한 이론식에 의해서 CMS-100 프로그램에 의해서 구한 부식전류밀도를 Fig. 6에 보여주고 있다.

$$
\mathrm{i}=\mathrm{icor}\{\exp (-\alpha \mathrm{nF} / \mathrm{RT})-\exp (\beta \mathrm{nF} n / \mathrm{RT})\},(1-\alpha=\beta)
$$

icor $=\frac{1}{n} \cdot \frac{\beta_{c} \cdot \beta_{a}}{2.3\left(\beta_{c}+\beta_{c}\right)} \quad\left(\beta_{c}=\frac{2.3 R T}{\alpha n F} \quad, \quad \beta_{a}=\frac{2.3 R T}{\beta n F}\right)$

$$
\begin{aligned}
& \mathrm{i}: \text { 공급전류밀도 }\left(\mathrm{A} / \mathrm{cm}^{2}\right) \\
& \mathrm{icor}: \text { 부식전류밀도 }\left(\mathrm{A} / \mathrm{cm}^{2}\right) \\
& \mathrm{R} \text { : 기체사ㅇㅜㅜ }\left(8.3144 \mathrm{~J} \cdot \mathrm{mol}^{-1} \cdot \mathrm{k}^{-1}\right) \\
& \mathrm{T}: \text { 절대온도 }(298 \mathrm{k}) \\
& \mathrm{a} \text { : 천이계수 } \\
& \mathrm{F} \text { : Faraday 상수 }(96500 \mathrm{C} / \mathrm{mol}) \\
& \mathrm{n} \text { : 이온가 } \\
& \mathrm{n} \text { : 분극전위 }(\mathrm{V})
\end{aligned}
$$

Fig. 6에서 알 수 있듯이 열처리를 한 경우가 열처리를 하지 않은 경우에 비해서 부식전류밀도가 확실히 감소하는 경향을 알 수 있다. 그리고 $500{ }^{\circ} \mathrm{C}$ 에서 유지시간이 길수록 부식전류밀도는 점진적으로 감소하는 경향이 있었으며 48 시간에서 가장 적은 전류밀도 값을 나타내고 72 시간에서는 다시 부식전류밀도가 증가하는 경향이 있음을 알 수 있다.

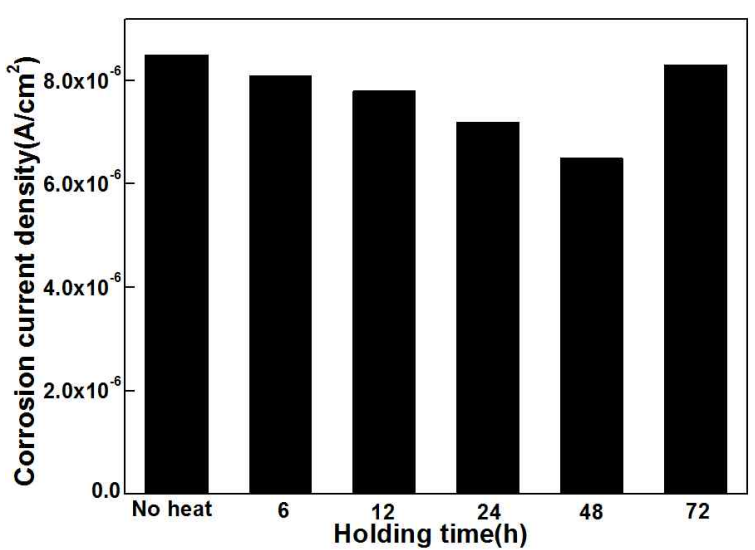

Fig. 6. Relationship between corrosion current densities and holding times(h) at $500{ }^{\circ} \mathrm{C}$.
FIg. 3의 조직사진에서 알 수 있듯이 열처리를 하지 않은 경우 결정립이 미세하고 $\beta^{\prime}$ 상과 $\gamma_{2}$ 상이 많이 존재하며 특 히 결정입계에 $\gamma_{2}$ 상이 많이 존재하고 있음을 알 수 있었다. 따라서 이들 상이 선택적으로 양극으로 작용하여 공식이 발 생되며 부식전류밀도는 증가하는 것으로 생각된다. ${ }^{11)}$ 그리 고 열처리에 의해서 결정립은 조대화 되고 점진적으로 $\beta^{\prime}$ 상과 $\gamma_{2}$ 상은 감소하며 특히 결정입계의 $\gamma_{2}$ 상이 많이 감소 하여 부식형태는 균일부식으로 변하면서 부식전류밀도는 감소하는 것으로 판단된다. 특히 48시간에서 내식성이 가장 좋은 것은 결정립이 조대화 되고 결정입계가 다른 유지시간 에 비해서 거의 보이지 않음을 알 수 있다. 이것은 결정입계 에 $\gamma_{2}$ 상이 거의 존재하지 않기 때문이며 따라서 완전한 균 일부식의 발생으로 인하여 내식성이 좋은 것으로 생각된다. 또한 72 시간에서 다시 내식성이 저하하는 경향은 지나친 열처리 시간에 의한 인공시효의 영향으로 결정입계사이의 경계면에 $\gamma_{2}$ 상이 다시 나타나는 것에 기인하는 것으로 생각 되나, 향후 좀더 구체적인 연구고찰이 필요할 것으로 생각된 다.

Fig. 7 은 $500{ }^{\circ} \mathrm{C}$ 에서 유지시간 변화에 따른 첫 번째 사이 클릭 볼타모그램의 변화를 보여주고 있으며 Fig. 8은 30번 째의 사이클릭 선도변화를 보여주고 있다. $-0.65 \mathrm{~V}(\mathrm{SCE})$ 에서 양극분극을 시작하여 약 $-0.1 \mathrm{~V}(\mathrm{SCE})$ 부근까지 부동 태상태를 유지한 후 $0.2 \mathrm{~V}(\mathrm{SCE})$ 까지 공식전위영역으로 이 행하면서 양극분극곡선을 그린 후 $0.2 \mathrm{~V}(\mathrm{SCE})$ 을 정점으로 다시 음극분극으로 전환하여 분극전위는 낮은 방향으로 하 강하면서 약 $-0.3 \mathrm{~V}(\mathrm{SCE})$ 영역 전후에서 음극부동태 한계 전류밀도를 나타낸 후 $-0.65 \mathrm{~V}(\mathrm{SCE})$ 의 전위로 되돌아 오 고 있음을 알 수 있다. 그런데 일반 구조용강 등에서는 거의 나타나지 않는 음극부동태 한계전류밀도가 유지시간에 관

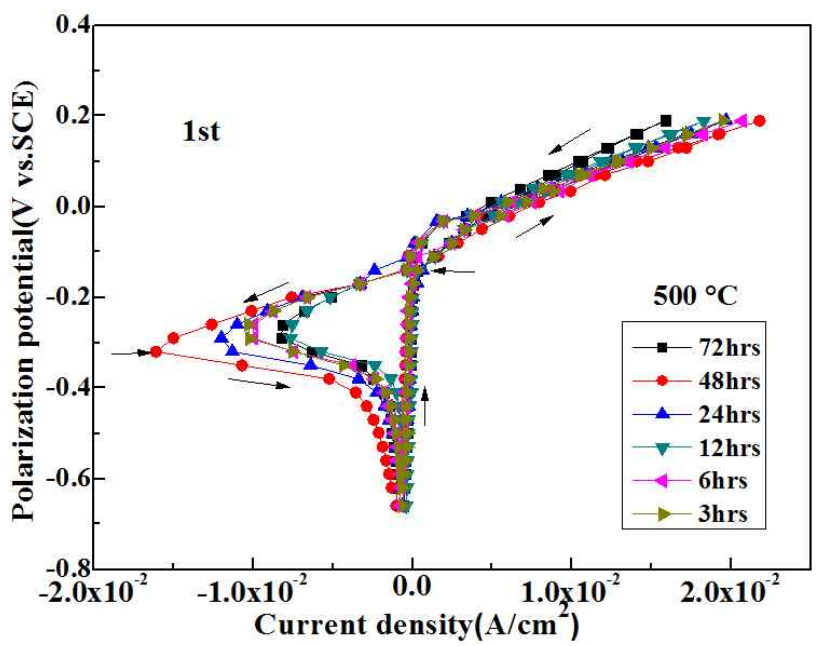

Fig. 7. Variation of 1st cyclic voltammogram curves with various holding time(h). 
계없이 본 실험의 알루미늄-규소 청동에서 나타난 것은 흥 미로운 사실이라고 생각된다. 이처럼 분극전위가 하강시에 음극환원전류 및 음극부동태 한계전류밀도가 나타난 것은 Table 1에서 알 수 있듯이 구리를 비롯한 금속성분이 양극 분극시에 표면에 치밀한 산화막의 형성에 의하여 원래의 낮 은 부식전위가 부동태 상태의 높은 영역으로 부식전위가 이 동하였기 때문으로 생각된다. ${ }^{14)}$ 예를 들면 초기에 양극 분극 의 경우 공급전류밀도 $\mathrm{i}_{\mathrm{pa}}=\mathrm{i}_{\mathrm{a}}-\mathrm{i}_{\mathrm{c}}\left(\mathrm{i}_{\mathrm{a}}\right.$ : 양극전류밀도, $\mathrm{i}_{\mathrm{c}}$ : 음극전류밀도) 이다. 따라서 전위가 양극분극에 의하여 상 승할 경우 낮은 부식전위에서 출발하여 양분극되므로 이때 공급전류밀도 $\mathrm{i}_{\mathrm{pa}}$ 가 플러스전류를 나타 내며 그 이유는 $\mathrm{i}_{\mathrm{pa}}$ $=\mathrm{i}_{\mathrm{a}}-\mathrm{i}_{\mathrm{c}}$ 에서 음극전류밀도 $\mathrm{i}_{\mathrm{c}}$ 가 $\mathrm{i}_{\mathrm{a}}$ 보다 적거나 제로이기 때문으로 생각된다.

그런데 분극전위가 하강함에 따라 즉 $0.3 \mathrm{~V}(\mathrm{SCE})$ 부근의 분극전위 전후에서 음극환원 전류밀도 나타난 것은 이미 초기에 양극분극에 의한 전위의 상승과 함께 시험편 표면의

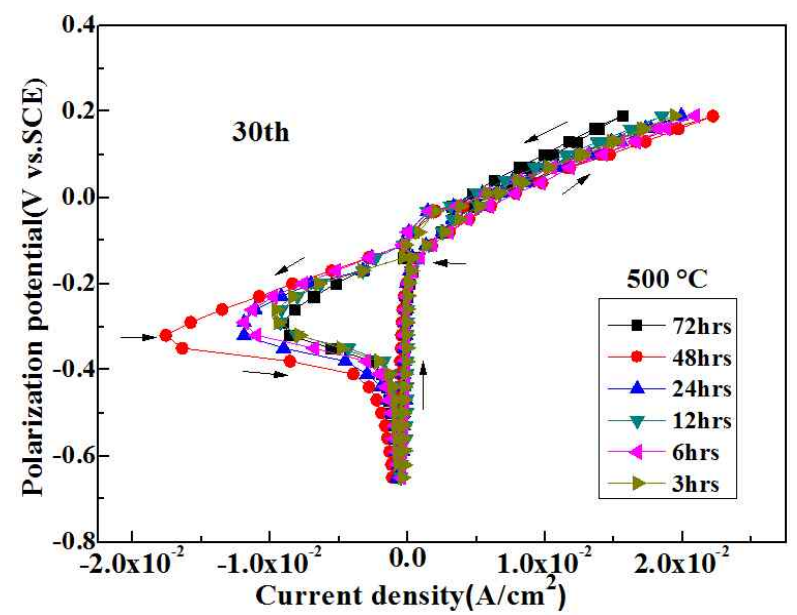

Fig. 8. Variation of 30 th cyclic voltammogram curves with various holding time(h).

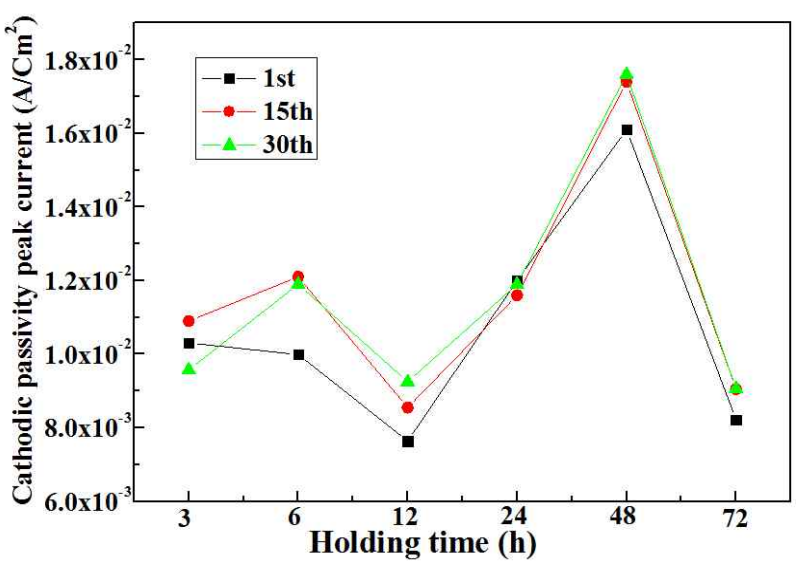

Fig. 9. Comparison of cathodic peak current densities with holding time and cyclic numbers
산화막의 형성에 의해서 이미 높은 전위에서 부식전위가 형 성되었으므로 $-0.3 \mathrm{~V}(\mathrm{SCE})$ 부근의 분극전위는 높은 부식전 위에서 음극 분극된 상태(음극분극곡선을 측정한 경우와 같 음)이며 이때의 음극전류밀도는 용존산소 환원반응에 따른 환원전류밀도 $\left(\mathrm{i}_{\mathrm{c}}\right)$ 이다. 이 경우 $\mathrm{i}_{\mathrm{a}}$ 는 $\mathrm{i}_{\mathrm{c}}$ 보다 적거나 제로라고 생각된다. ${ }^{14)}$ 따라서 음극부동태 한계전류밀도 $\left(\mathrm{i}_{\mathrm{c}}\right)$ 가 큰 시 험편은 표면에 치밀한 산화막의 형성에 의해서 $\mathrm{i}_{\mathrm{a}}$ 가 상대적 으로 적은 즉 내식성이 다른 시험편에 비해서 우수하다고 생각된다.

Fig. 9는 사이클릭 수와 음극부동태 한계전류밀도와의 관 계를 나타내고 있다. Fig. 9에서 알 수 있듯이 48시간의 경우가 음극부동태 한계전류밀도가 가장 큰 값을 나타내고 있음을 알 수 있다. 그리고 Fig. 4와 Fig. 6에서 48시간에서 의 부식전류밀도 역시 가장 적은 값을 나타내었다. 따라서 음극부동태 한계전류밀도가 클수록 내식성이 좋은 경향을 나타내는 것으로 판단된다. 한편 본 실험에 사용한 알루미늄 -규소청동의 주요 금속성분은 구리, 알루미늄 및 규소이다. 전위- $\mathrm{pH}$ 도 ${ }^{15)}$ 에 의하면 이들 성분의 평형전위식은 다음과 같다.

$$
\begin{aligned}
& \mathrm{Al}+3 \mathrm{H}_{2} \mathrm{O} \rightarrow \mathrm{Al}_{2} \mathrm{O}_{3}+6 \mathrm{H}^{+}+6 \mathrm{e} \\
& \mathrm{E}=-1.471-0.0591 \mathrm{pH} \\
& 2 \mathrm{Cu}+\mathrm{H}_{2} \mathrm{O} \rightarrow \mathrm{Cu}_{2} \mathrm{O}+2 \mathrm{H}^{+}+2 \mathrm{e} \\
& \mathrm{E}=0.471-0.0591 \mathrm{pH} \\
& \mathrm{Si}+\mathrm{H}_{2} \mathrm{O} \rightarrow \mathrm{SiO}_{2}+4 \mathrm{H}^{+}+4 \mathrm{e} \\
& \mathrm{E}=-0.807-0.0591 \mathrm{pH}
\end{aligned}
$$

사이클릭선도에서 양극분극에 의한 산화반응시에 표면에 는 상기의 1,2 및 3 식에 의한 치밀한 산화막이 형성되어 부동태 상태가 되며 음극 분극시에도 이들 산화막에 의해서 치밀한 부동태상태에 있으므로 높은 부식전위를 형성하게 되어 전위의 하강에 따라 상대적으로 양극전류는 적어져서 음극환원전류가 크게 흐르는 것으로 생각된다. Fig. 10은 사이클릭선도를 측정한 후 200 배의 배율로 관찰한 부식된 표면상태를 보여주고 있다. 열처리를 하지 않은 경우 표면에 일종의 공식현상이 나타나고 있음을 알 수 있다. 그리고 열 처리에 의해서 점차 공식현상이 감소하고 균일부식으로 변 하는 경향이 있으며 48시간에서는 공식이 거의 관찰되지 않았다. 전술한 바와 같이 열처리를 함으로써 결정립이 조대 화되고 점진적으로 $\beta^{\prime}$ 상과 $\gamma_{2}$ 상은 감소하며 특히 결정입 계의 $\gamma_{2}$ 상이 많이 감소하여 공식이 억제되는 것으로 생각된 다. 결과적으로 열처리에 의해서 공식의 억제에 의한 내식성 의 개선효과를 얻을 수 있다고 판단되었다. 


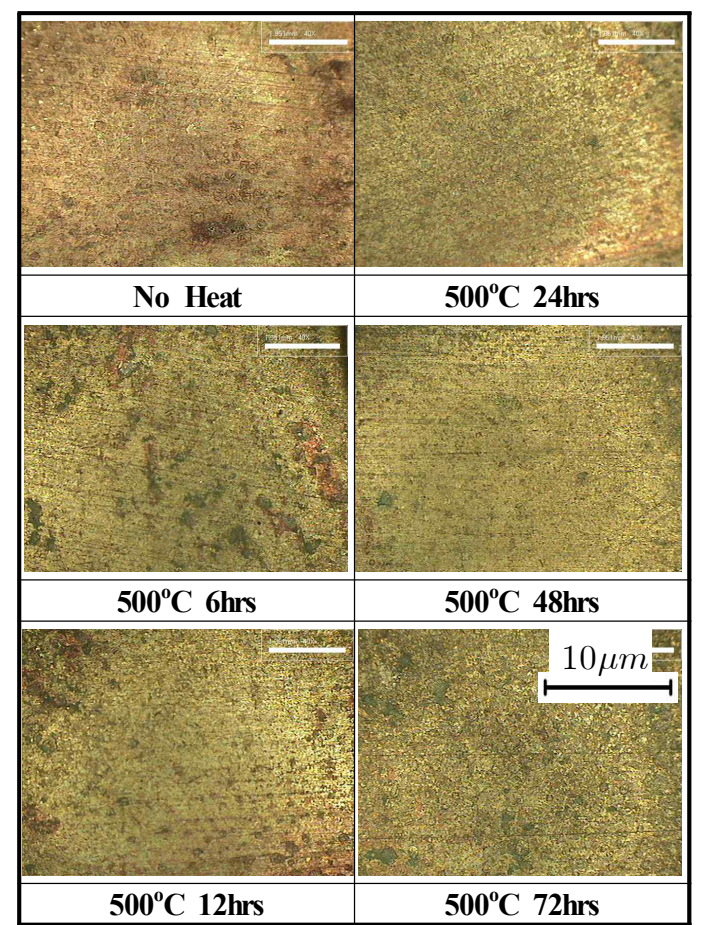

Fig. 10. Morphologies of the corroded surfaces after drawing cyclic voltammogram curves.

Fig. 11은 각 시험현에 대한 임피던스변화를 나타내고 있 다. $0.1 \mathrm{~Hz}$ 에서 12 시간의 경우 가장 높은 임피던스값을 나 타내고 있으며 24시간에서 가장 적은 값을 나타내었다. 본 실험의 임피던스값과 내식성의 상관관계는 잘 일치하지 않 음을 알 수 있다. 시험편의 표면에 형성된 부식생성물이 저 항분극으로 작용하여 임피던스에 영향을 미치기 때문에 임 피던스값의 변화만으로 내식성의 정도를 정성적으로 평가 하는 것은 어려움이 있는 것으로 판단된다.

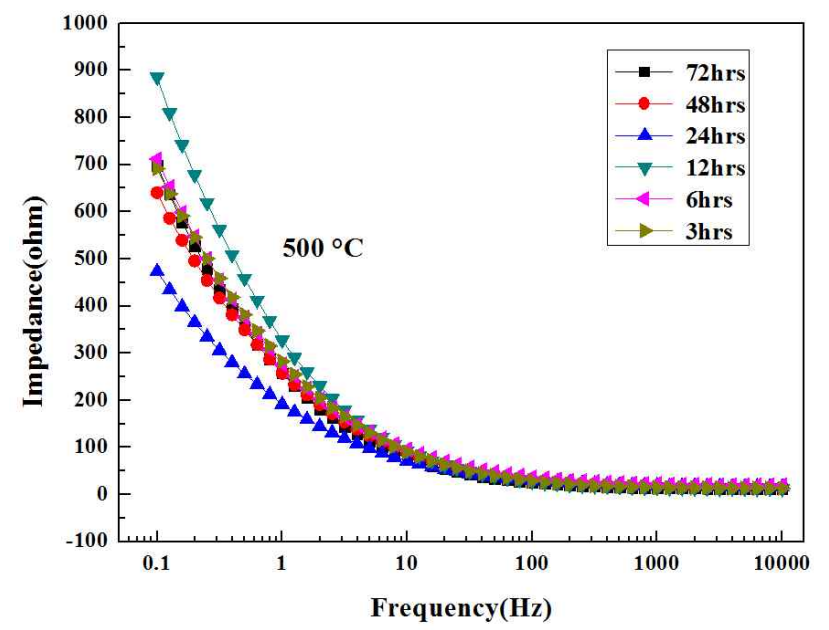

Fig. 11. Bode plots of the test specimens with holding time at $500{ }^{\circ} \mathrm{C}$.

\section{4. 결 론}

지금까지 원심 주조한 알루미늄-규소청동을 $500^{\circ} \mathrm{C}$ 의 일 정온도에서 유지시간을 변수로 열처리했을 때 기계적 성질 과 내식성에 미치는 효과에 대해서 비교 고찰한 결과 다음과 같은 결론을 얻을 수 있었다.

1. 열처리를 한 경우 열처리온도의 유지시간에 관계없이 열 처리를 하지 않은 경우에 비하여 약간의 경도저하가 있었 으며 특히 48 시간동안 열처리 했을 때 경도의 저하가 가 장 컸었다.

2. 원심주조에 사용되는 회전 금형이 수냉되기 때문에 급냉 에 의한 열처리효과로 인하여 원심주조재의 조직에서 $\alpha$ 상 뿐만 아니라 $\beta^{\prime}$ 상과 $\gamma_{2}$ 상도 관찰 되었다.

3. 열처리에 의해서 결정립의 조직이 조대화 되는 경향을 나타 내었으며 그리고 열처리에 의해서 $\beta^{\prime}$ 상과 $\gamma_{2}$ 상이 감소하는 경향을 나타 내었다.

4. 열처리를 하지 않은 경우 $\gamma_{2}$ 상이 양극으로 작용하여 공 식현상이 관찰되었으나, 열처리에 의해서 $\gamma_{2}$ 상의 감소로 인하여 균일부식으로 변화하면서 내식성이 향상되었다. 특히 48시간 열처리 했을 때 가장 내식성이 우수한 결과 를 얻을 수 있었다.

5. 본 실험의 결과 열처리에 의해서 약간의 경도저하는 있었 으나 내식성의 개선효과를 얻었다.

\section{References}

1. Y. S. Yhou, Material Science of Nonferrous Metals, korona publication. Co. Ltd., Japan, p. 68 (1963).

2. D . P. Cox, Copper Resources in Ency Clopedia of Materials Science and Engineering, 2, M. B Beven. Ed, Dergamon Press and the MIT Press, p. 855 (1986).

3. T. Cunningham, Marine Coating Inspection Program, Version 97-1, NACE International Houston, Texas (1997).

4. T. Cunningham, The Marine Enviroment, Version 97-1, NACE International Houston, Texas (1997).

5. Cathelco, ANTIFOULING SYSTEM OPERATION MANUAL, Marine house Hipper Street South, HULL SB-395 (1976).

6. Marine Fouling and Its Prevention, U. S. Naval Institute, Annapolis, Md (1952).

7. C. Hans. C. Flemming, G. Gill, K. Geesey, Biofouling and Biocorrosion in Industrial Water System, International Workshop on Industrial Biofouling and Biocorrosion, Stuttgant, p. 13 (1990).

8. Standard Method for Testing Antifouling Panels in Shallow Submergence, ASTM, D 3623-78a (1993).

9. J. R. Davis, Copper and Copper Alloy, ASM SPECIALTY HANDBOOK, ASM International, p. 47 (2001),

10. N. J. Bak, Material Science of Metals, Kwang Lim Publication. Co. Ltd., Korea, p. 313 (1983).

11. Y. S. Yhou, Material Science of Nonferrous Metals, korona 
publication. Co. Ltd., Japan, p. 85 (1963).

12. A. Bard and L. R. Faulkner: Electrochemical Methods Fundamental and Applications, Department of Chemistry University of Texas and Illinois, p. 103 (1980).

13. K. M. Moon, Practical Electrochemistry, Hyosung publication. Co. Ltd., p. 136 (2000).
14. I. Dou, Corrosion Science and Protection Technology, edited by korona Co. Ltd., p. 144 (1979).

15. M. Pourbaix and N. DE Zoubov, Atlas of Electrochemical Equilibrium in Aqueous Solution, ed. pergamon press and cebelcor, p. 169 (1966). 